\title{
Invited review: Effects of heat stress on dairy cattle welfare
}

\author{
Liam Polsky and Marina A. G. von Keyserlingk ${ }^{1}$ \\ Animal Welfare Program, 2357 Main Mall, Faculty of Land and Food Systems, University of British Columbia, Vancouver, BC, V6T 1Z4 Canada
}

\section{ABSTRACT}

The effects of high ambient temperatures on production animals, once thought to be limited to tropical areas, has extended into northern latitudes in response to the increasing global temperature. The number of days where the temperature-humidity index (THI) exceeds the comfort threshold $(>72)$ is increasing in the northern United States, Canada, and Europe. Compounded by the increasing number of dairy animals and the intensification of production, heat stress has become one of the most important challenges facing the dairy industry today. The objectives of this review were to present an overview of the effects of heat stress on dairy cattle welfare and highlight important research gaps in the literature. We will also briefly discuss current heat abatement strategies, as well as the sustainability of future heat stress management. Heat stress has negative effects on the health and biological functioning of dairy cows through depressed milk production and reduced reproductive performance. Heat stress can also compromise the affective state of dairy cows by inducing feelings of hunger and thirst, and we have highlighted the need for research efforts to examine the potential relationship between heat stress, frustration, aggression, and pain. Little work has examined how heat stress affects an animal's natural coping behaviors, as well as how the animal's evolutionary adaptations for thermoregulation are managed in modern dairy systems. More research is needed to identify improved comprehensive cow-side measurements that can indicate real-time responses to elevated ambient temperatures and that could be incorporated into heat abatement management decisions.

Key words: well-being, affective state, natural behavior, body temperature, cow

Received January 26, 2017.

Accepted July 17, 2017.

${ }^{1}$ Corresponding author: nina@mail.ubc.ca

\section{INTRODUCTION}

Escalating global temperatures (Schär et al., 2004) combined with global increases in the number of production animals and the intensification of agriculture (Renaudeau et al., 2012), including (but not limited to) that in emerging economies (von Keyserlingk and Hötzel, 2015), has resulted in heat stress becoming an important challenge facing the global dairy industry.

Given that lactating dairy Bos taurus cows already have elevated internal heat loads caused by high milk production (Chebel et al., 2004), the effects of accumulating incremental heat are exacerbated when temperature and humidity values increase in the surrounding environment (West, 2003). Not surprisingly, these challenges are greatest in geographic areas where the summer season is long (i.e., southwestern United States, Brazil) and there is a constant presence of radiant solar energy and high humidity, resulting in minimal relief from the heat (Schüller et al., 2014). However, animals housed in northern latitudes (i.e., central Europe, northern United States, Canada) can also experience heat stress, where the summer season is relatively short but warm and there is a minimal decline in overnight temperatures. Heat stress results in total annual economic losses to the US livestock production industry ranging from $\$ 1.69$ to 2.36 billion, of which $\$ 900$ million is specific to the US dairy industry, stemming from decreased milk production, compromised reproduction, and increased culling (St-Pierre et al., 2003).

Heat stress is defined as the sum of external forces acting on an animal that causes an increase in body temperature and evokes a physiological response (Dikmen and Hansen, 2009). Excessive flow of energy (in the form of unabated heat) into the body, in addition to energy depletion required for lactation and growth (Ferrell and Jenkins, 1985) can lead to deteriorated living conditions, reduced quality of life, and, in extreme cases, death (Mader et al., 2006), unless the animal can activate various adaptive mechanisms to increase the external net energy flow. Documented physiological coping strategies used by dairy cows include increased respiration rate, panting, and sweating, and reduced milk yield and reproductive performance. Behavioral coping strategies include modified drinking and feed 
intake (e.g., increased water intake and shifting feeding times to cooler periods during the day), increased standing time and shade seeking, and decreased activity and movement (De Rensis and Scaramuzzi, 2003; West, 2003; Schütz et al., 2008).

The environmental conditions driving heat stress are presented using the temperature-humidity index (THI), a calculated index that incorporates the effects of environmental temperature with relative humidity. This unitless index was first introduced by Thom (1959) to describe the effect of ambient temperature on humans but has been adapted to describe thermal conditions that drive heat stress in dairy cattle (De Rensis et al., 2015). The THI is divided into categories that potentially indicate the level of heat stress, but definitions vary between researchers and conditions. Armstrong (1994) used THI $<71$ as a thermal comfort zone (assuming the THI does not drop below the thermoneutral conditions of dairy cows, which induces cold stress), 72 to 79 as mild heat stress, 80 to 90 as moderate heat stress, and $>90$ as severe heat stress. Comparatively, De Rensis et al. (2015) defined THI $<68$ to be outside the thermal danger zone for cows. Mild signs of heat stress are observed at THI of 68 to 74 , and a THI $\geq 75$ will cause drastic decreases in production performance (De Rensis et al., 2015). The THI value is usually the main determinant for management decisions related to heat stress as most meteorological stations close to farms provide this data.

However, the categorical THI values described above (although dependent on the geographic location, as well as cow breed and physical size) can only act as a rough indicator for the effects of heat stress on production measures, in lieu of knowing the animal's internal body temperature. Moreover, calculating environmental heat stress is dependent on which formula is chosen, as THI equations can weight humidity or dry-bulb temperature to account for different environmental conditions (Bohmanova et al., 2007). Wind speed has also been shown to affect environmental temperatures (Mader et al., 2006) and should be included in THI calculations when possible.

Most of the scientific literature on the effects of heat stress on dairy cattle has focused on physiological measures that describe how the animal is interacting with its environment, such as plasma cortisol, heart rate, and respiratory rate (Kadzere et al., 2002). However, physiological measures at best describe the health and biological functioning component of the animal's welfare but fail to address the multidimensional concept of animal welfare that also considers aspects such as mental states (i.e., the absence of pain and frustration), and the ability to live a reasonably natural life (Fraser et al., 1997; Boissy et al., 2007).
Negative feelings such as pain or frustration are increasingly described as suffering (Duncan, 2004). Clearly, when animals lose the ability to control their environment (e.g., a need for water to alleviate dehydration, the need for shade to reduce body temperature), there are associated risks to the animal's welfare that may not necessarily be associated with direct biological functioning. The subjectivity of feelings in animals, including cattle, is difficult to quantify and describe, but scientists have begun to evaluate them using experimental approaches such as preference and motivation testing (Schütz et al., 2008; Charlton et al., 2013; von Keyserlingk et al., 2017) and judgement bias tests (Daros et al., 2014).

A key objective of animal welfare science, as argued by some, is to determine which aspects of natural living are important for animals and how producers can incorporate these needs into best management practices (Fraser et al., 1997). This component of animal welfare has received much debate, as some view natural living to literally mirror the animal's "evolutionary" environment (e.g., grazing on pasture and calves suckling their dam) and how producers can promote their animals to express these behaviors. In contrast, others argue that this interpretation and application of natural living into management practices may negatively affect welfare (e.g., by exposing the animal to diseases, parasites, extreme weather, and predators; Špinka, 2006). Recent research investigating dairy producer attitudes toward animal welfare highlights farmers' concerns for animals' subjective and natural living (Ventura et al., 2015), and ultimately, we see natural living solutions as being a balance of both interpretations so that farm animals can live a "good life."

An essential foundation for welfare science is that different concerns of animal welfare can overlap each other. A lactating cow unable to seek shade on a hot day (natural living) will likely feel uncomfortably hot (affective state) and will experience reduced milk production (poor biological functioning; von Keyserlingk et al., 2009). Most research has addressed welfare issues in a manner where the concern can be subjected to and assessed using scientific investigation through one sphere of animal welfare (i.e., lameness as a component of biological functioning and health; motivation to access pasture as a component of natural living). However, personal values of researchers often dictate the direction of scientific inquiry and may prevent new approaches from being considered and investigated (e.g., lameness as a component of affective states). Unfortunately, heat stress research has followed this same dogma; thus, in this review, we propose new avenues of discussion in an attempt to reframe how we think of heat stress and dairy cattle welfare. For example, for 
the purposes of this review, we have elected to discuss lameness from an affective state perspective (given that there is a growing body of evidence that this malady is painful) and not, as most have done, from the position of biological functioning and health.

The objective of this review was to take a broad approach to assessing the effects of heat stress on dairy cattle welfare by using the 3 key constructs of animal welfare originally defined by Fraser et al. (1997) and then modified for dairy cattle by von Keyserlingk et al. (2009): (1) the biological functioning (and health) of the animal; (2) the affective states the animal is experiencing; and (3) the naturalness of its life under current heat management strategies (Figure 1). Based on the available literature, the majority of the review will focus on the dairy cow in North American confinement housing (with brief examples from pasture-based herds) but when applicable, evidence from other mammalian species is discussed.

\section{HEALTH AND BIOLOGICAL FUNCTIONING}

Good health is central to animal welfare because it is indicative of the animal's physiological functioning
(Fraser et al., 1997). Producers are committed to the health and nutrition of their livestock, as this approach normally results in high levels of milk production reflective of their genetics and acceptable reproduction rates, thereby increasing the efficiency and profitability of the dairy farm (Te Velde et al., 2002). Beef producers also emphasize the importance of promoting strong biological functioning and health as a component of welfare management practices, as well as its inextricable relationship with productivity (Spooner et al., 2012). Mortality is the ultimate beacon of a poor quality of life for animals but clearly should only be considered a crude indicator for health (von Keyserlingk et al., 2009). There is no doubt that the use of prompt and sensitive markers indicative of biological functioning can improve health monitoring (Cray et al., 2009), and may allow for proactive treatment before animals become ill and experience severely depressed biological functioning. Although body temperature (vaginal or rectal) or respiration rate (panting frequency) provides valuable information for the relationship between the animal and the environment, both measures are impractical to consistently monitor on a large production scale, and discontinuous sampling times may not ac-

\section{ELEVATED EN VIRONMENTAL TEMPERATURES}

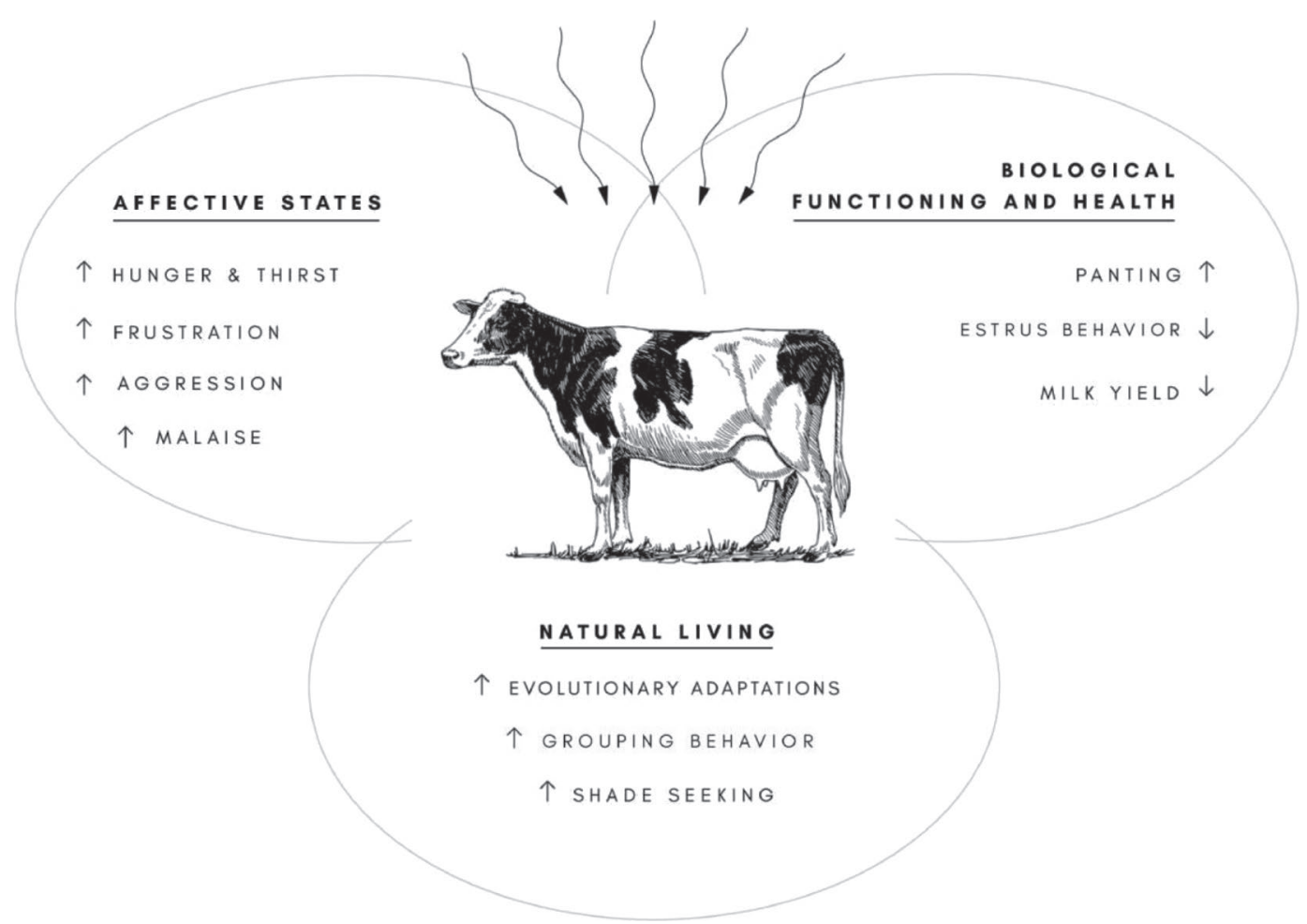

Figure 1. The relationship between the immediate effects of environmental heat stress and the 3 key constructs of animal welfare: (1) the biological functioning (and health) of the animal, (2) the affective states the animal is experiencing, and (3) the naturalness of its life under current heat management strategies. 
curately represent the animal's experience of heat load (Bewley et al., 2008). We recognize that numerous factors fall within this construct but will, for the purposes of this review, focus on the use of milk production and reproductive performance as welfare indicators for the biological functioning of heat-stressed dairy cows.

\section{Heat Stress Decreases Milk Production}

Lactating dairy cows have an increased sensitivity to heat stress compared with nonlactating (dry) cows, due to milk production elevating metabolism (Purwanto et al., 1990). Moreover, because of the positive relationship between milk yield and heat production, higher yielding cows are more challenged by heat stress than lower yielding animals (Spiers et al., 2004).

When a cow becomes heat stressed, an immediate coping mechanism is to reduce DMI, causing a decrease in the availability of nutrients used for milk synthesis (West, 2003; Rhoads et al., 2009). Simultaneously, there is an increase in basal metabolism caused by activation of the thermoregulatory system. Mild to severe heat stress can increase metabolic maintenance requirements by 7 to $25 \%$ (NRC, 2001), further exacerbating both the existing metabolic stress and the decrease in milk production.

Decreased milk production has been used in some studies as an indicator for reduced welfare for animals that are already challenged by various diseases such as mastitis (Gröhn et al., 2004). Rushen et al. (2001) demonstrated that milk yield declines instantly when cows are exposed to stressful or unfamiliar environments. As a result, it is often assumed that milk production can be interpreted to be a direct welfare indicator in that it offers producers the ability to monitor the animal's individual response to a challenging event (e.g., increasing ambient temperature or changes in nutrition). However, others have challenged the use of milk production as an acceptable welfare indicator (von Keyserlingk et al., 2009), particularly for heat-stressed cows, due to the confounding effects of decreased DMI and the delayed decline in milk production following elevated ambient temperatures.

Following periods of warmer environmental temperatures, there is usually a lag before milk yield declines. Collier et al. (1981) reported a 24- to 48-h delay between elevated environmental temperatures and decreased milk production. Additional evidence provided by Linvill and Pardue (1992) indicated that milk production only begins to decline when the THI consistently exceeds 74 during the previous 4 d. Clearly, if milk production changes are only identified in the days following heat stress, this measure is limited in that it only tells us that the animal was in heat stress and arguably experienced poor welfare but, given the lag, it is at best an indirect measure of welfare (von Keyserlingk et al., 2009).

Despite the documented challenges with using milk production per se as an indicator of welfare in lactating dairy cows, very recent evidence suggests that changes in milk composition may be more useful to assess cows in immediate heat stress (Hu et al., 2016). Future research is needed to determine whether cow-side tests that monitor acute changes in milk composition in response to heat stress can be practically implemented on farms.

\section{Heat Stress Decreases Reproductive Success}

The decrease in conception rates during summer seasons can range between 20 and $30 \%$, with evident seasonal patterns of estrus detection (De Rensis and Scaramuzzi, 2003). Elevated environmental temperatures negatively affect the cow's ability to display natural mating behavior, as it reduces both the duration and intensity of estrous expression (Orihuela, 2000). A reduction in estrous behavior has been argued to be the result of reduced DMI and the subsequent effects on hormone production (Westwood et al., 2002). Moreover, reduced estrous behavior may be attributed to man's domestication of bovine breeds, which has attempted to change the cow from a "seasonal" to "yearround" breeder. The cow's natural selection for seasonal breeding has been argued by some to be reduced due to improved feed quality and availability, improved health monitoring, and care for the calf (Hansen, 1985), thus reducing the need to express various components required for successful reproduction (uterine health, embryo quality, hormone concentrations) on a strictly seasonal basis. However, the encompassing effects of heat stress on reproduction are persistent and exacerbated in the summer months, and year-round breeding continues to be problematic for producers.

Hansen and Aréchiga (1999) reported reduced estrous behaviors in heat-stressed dairy cows. Those authors speculate that heat stress induces physical lethargy, which acts as a coping mechanism that limits further increases in the animal's internal heat production already caused by activity related to estrus. Additional evidence reports that estrous mounting behaviors in beef cattle are markedly decreased in total time and frequency during the summer compared with winter months (White et al., 2002). Moreover, shorter durations of estrus have been documented when European breeds such as B. taurus (compared with Bos indicus breeds) are moved to tropical areas, with differences attributed to temperature, nutrition, and parasites (Orihuela, 2000). 
Reproductive metrics have been used as a welfare indicator for cows in heat stress based on the premise that conception rates (De Rensis and Scaramuzzi, 2003), oocyte quality (Roth et al., 2001), and pregnancy loss (Silanikove, 2000) are all affected by elevated temperatures. However, these characteristics are determined retrospectively and thus only indicate that the animal was in heat stress at the time of, or surrounding, breeding. We therefore argue that these parameters are better used as management tools for future breedings and as evidence that improved strategies are needed to mitigate the effects of increased environmental temperatures. A more sensitive indicator of welfare is rectal temperature on the day of AI because conception rates at $60 \mathrm{~d}$ decline from 21 to $15 \%$ when rectal temperature is greater than $39.1^{\circ} \mathrm{C}$ during AI (Pereira et al., 2013).

Decreased milk production and declining reproductive success are the most commonly examined components of a heat-stressed dairy cow's health and biological functioning due to their ease of measurement at the herd level, and they have a direct link to farm profitability. Comparatively, the effects of ambient temperature on the affective states and natural living of heat-stressed animals have not been thoroughly examined but do provide essential information on the animal's welfare at the cow level.

\section{AFFECTIVE STATES}

How the animal feels as it experiences and perceives its surrounding environment is central to animal welfare, and developing validated measures of these states is one of the most challenging components of animal welfare science (von Keyserlingk et al., 2009). Substantial research has been conducted investigating negative affective states such as pain and suffering (see reviews by Weary et al., 2006; von Keyserlingk et al., 2009), and parallel research has examined positive affective states experienced by animals (Boissy et al., 2007; Bertenshaw et al., 2008; Weary et al., 2017).

Collins and Weiner (1968) first suggested that the initial reactions by dairy cows to acute heat stress could represent an emotional rather than a thermoregulatory response, as human emotional responses can elevate adrenal levels despite the absence of physical stimuli. This review will examine how negative stimuli such as hunger, thirst, and frustration, induced by heat stress, can negatively affect the animal's affective state.

\section{Heat Stress and Hunger}

The link between increasing environmental temperatures, body temperature, and decreased DMI has been clearly established (reviewed by West, 2003; Allen et al., 2015), but minimal work has examined the resulting effects of appetite and hunger caused by reductions in DMI or by feed composition changes during heat wave periods. Appetite refers to the subjective desire to eat, whereas hunger is a negative affective state experienced by an animal that is unable to become satiated (D'Eath et al., 2009). The concept of under-nourishing implies that the animal's intake is falling short of its "desired" intake. A heat stress-driven reduction in appetite and a decline in nutrient availability can lead to large BW loss, ultimately pushing the animal into physiological negative energy balance (Rhoads et al., 2009), accompanied by a reduction in the cow's BCS (Collard et al., 2000; Rhoads et al., 2011). It has been suggested that low BCS may contribute to a reduced welfare state in dairy cows, as their biological health is functioning at suboptimal levels (Roche et al., 2009). Verbeek et al. (2012) reported that ewes with a low BCS $(=2)$ were prepared to work harder for access to food compared with animals of higher BCS (3 or 4), providing some evidence that animals in low BCS were likely experiencing hunger.

The duration of elevated temperatures has an inverse relationship with DMI, and a short, simulated heat wave $\left(29^{\circ} \mathrm{C}, \sim 50 \%\right.$ relative humidity for $\left.4 \mathrm{~d}\right)$ has been shown to suppress feed intake as soon as $1 \mathrm{~d}$ after the rise in temperature (Spiers et al., 2004). Ghrelin, a hormone produced by ghrelinergic cells in the gastrointestinal tract, is secreted when the stomach is empty in attempts to increase hunger and gastrointestinal mobility (Pearce et al., 2014). Heat stress increases the expression of ghrelin from the glandular stomach and small intestines of broiler chickens (Lei et al., 2013), laying hens (Song et al., 2012), and pigs (Pearce et al., 2014). We postulate that despite "voluntary" decreases in DMI, dairy cows subjected to heat stress may have increased ghrelin secretion and may be experiencing hunger.

Variations in vocalizations demonstrated by piglets are related to degree of need (Weary and Fraser, 1995), and increased vocalizations are common during dairy calf weaning, often indicative of hunger stemming from a reduced milk allowance (Thomas et al., 2001). Vocalizations by dairy cows during distressing situations (e.g., social isolation, pain, or hunger) are common (reviewed by Watts and Stookey, 2000), thus we hypothesize that extreme environmental temperatures may act as a stressor, thereby inducing the same distressing vocalization response. Moreover, heat-stressed cows can experience malaise stemming from low satiety as well as hunger caused by unbalanced diets (Roche et al., 2009), prompting further behavioral responses. Additional research is required to elucidate the relationship between gastric neuromuscular and neurohormonal mediators 
of heat stress and hunger to better understand eating behavior under times of elevated heat load and the subsequent effects on the animal's affective state.

To mitigate decreases in DMI while sustaining milk production, farm managers will often increase the energy density of the diet by reducing the concentration of forage and increasing the concentrate portion of the diet (Renaudeau et al., 2012). However, the increased catabolism of urea caused by elevated protein digestion increases the concentration of blood nonprotein nitrogen (NPN). Blood NPN concentrations are positively correlated with increased rectal temperatures (Hassan and Roussel, 1975), suggesting that protein digestion elevates internal temperature. Clearly, strategies used to mitigate the negative effects of reduced DMI can have downstream consequences that further exacerbate the effects of heat stress. Future research should aim to refine heat stress dietary solutions that satisfy the animal's production requirements while prioritizing the animal's optimal biological functioning and taking into consideration the other concepts of welfare.

\section{Heat Stress and Thirst}

In mammals, the 4 primary routes of water loss are cutaneous and pulmonary evaporation, feces, and urine. Some species, such as camels (Camelus dromedarius) and Bedouin goats (Capra hircus) can survive 30 to 40\% BW water loss (Cain et al., 2006). Dairy cattle, in contrast, experience severe dehydration symptoms at 12\% BW water loss (Roussel, 1999).

Water accessibility is the most important resource for a heat-stressed dairy cow, and the supply of fresh water on hot days should not be overlooked. Water intake will increase by $1.2 \mathrm{~kg} /{ }^{\circ} \mathrm{C}$ above minimum ambient temperature (West, 2003), and providing chilled drinking water $\left(10^{\circ} \mathrm{C}\right)$ can lower body temperature and respiration rates (Wilks et al., 1990). However, in extreme cases of heat stress, an animal's thirst can be inhibited or completely depressed by altered mental states induced by hyperthermia (Ganong, 2005). In this situation, the animal enters a detrimental cascade of events in which the inability to satisfy thirst compounds the existing dehydrating effects of heat stress (i.e., increased respiration rate, panting, sweating), further exacerbating the altered mental state (Ganong, 2005).

The behavioral response elicited by heat stress can vary based on species as well as the animal's perceived threat of temperature. Pritchard et al. (2006) showed that dehydration negatively affects spatial awareness and coordination in donkeys, and research conducted on humans provides additional evidence that hyperthermia contributes to neuromuscular fatigue (Nybo and Nielsen, 2001). Future research should investigate the link between hyperthermia, dehydration, and coordination in dairy cows, as increases in movement (i.e., walking on pasture, to/from the milking parlor, individual and collective herd behavior) may increase their susceptibility to injury in hot climates.

Skin tenting is a classic sign of dehydration in animals (Ettinger and Feldman, 2009) and can be used to assess animal welfare. Pritchard et al. (2005) examined $\sim 5,000$ draft, pack, and work animals, and found that $37 \%$ of donkeys and $50 \%$ of horses showed an increase in skin tenting, whereas fewer than $4 \%$ of those animals showed clinical behavioral signs of heat stress (increased panting, flared nostrils, apathy). These results suggest that the welfare of the animal, at least of working equines, begins to be compromised before behavioral responses have been initiated, and that solely using behavior to indicate heat stress does not always accurately represent the animal's immediate physiological (dehydration) or mental (thirst) state. More research is needed to examine this relationship in dairy cows, as horses have a higher capacity to exchange heat via sweating compared with cattle.

\section{Lameness, Pain, and Heat Stress}

Pain and discomfort are the most frequently studied negative affective states in animal welfare literature (reviewed by Weary et al., 2006). Although "discomfort" lacks a precise scientific definition, the International Association for the Study of Pain defines pain as an "unpleasant sensory and emotional experience associated with actual or potential tissue damage" (IASP 1994). Current research methodologies that aim to assess animal pain normally use 1 of 3 approaches: measures of body functioning (i.e., water, DMI), physiological responses (i.e., hypothalamic-pituitary-adrenal axis activation), or behavioral measurements (e.g., vocalizations, lying and standing duration and bouts) (Weary et al., 2006). This review will focus on pain caused by lameness as a contributor to the animal's negative affective state and how this malady may be affected by heat stress.

Cows under increased heat load change their behavior in an effort to improve cooling. Notably, heat-stressed cows have been reported to increase their standing time, and in turn decrease lying time and walking activity, to expose more surface area for heat abatement, sensible water loss, radiating surface area, and air movement via convection (Cook et al., 2007; Allen et al., 2015). Several studies examining the lying time of cows in freestalls report a range of 11 to $14 \mathrm{~h}$ (Cook et al., 2004a; Jensen et al., 2005; Ito et al., 2010) under thermo-neutral conditions, with a $30 \%$ reduction when ambient temperatures increase (Cook et al., 2007). 
Extended periods of prolonged standing have been argued by some to be a major risk factor for lameness (Cook and Nordlund, 2009; Allen et al., 2015), which may also be associated with painful experiences (Flower et al., 2008). It is not surprising that heat stress is considered a major risk factor for lameness (Cook et al., 2007), but whether this association is a consequence of increased standing times (Cook et al., 2007) or due to alterations in nutrient metabolism (Cook et al., 2004b) caused by a decrease in DMI is not known. Given that lameness has been associated with pain in dairy cattle (Whay et al., 1998; Flower et al., 2008), future research should disentangle the complex interaction between heat stress, lameness, and pain. Based on the available evidence to date, we speculate that heat stress may have a profound impact on behavior, biological functioning, and affective states of dairy cattle given that high ambient temperatures cause increased standing times, which in turn increases the risk of lameness and painful experiences.

\section{Frustration and Aggression Caused by Improper Cooling}

Similar to pain, current indicators of frustration in animals rely on changes in functioning and behavioral measures (Weary et al., 2006). Frustration is classically defined as the emotional state experienced when the animal fails to achieve expected gratification (LeDoux, 1995). Research investigating an animal's motivation for control and its desire for agency is a focal point in welfare research (Špinka and Wemelsfelder, 2011), as controlled effectiveness (the animal's motivation to manage its environment; Franks and Higgins, 2012) has been documented in rats (Franks et al., 2013), chickens (Lindqvist and Jensen, 2008), pigs (de Jonge et al., 2008), and cattle (Hessle et al., 2008). When an animal is motivated to change its environment (i.e., as a means to alleviate environmental temperatures), it will initiate a reward cycle where the strongest positive affective state occurs when the reward is acquired (e.g., in the case of heat stress - reduced internal temperature; Keeling et al., 2008). Some have argued that any interruption in the animal's motivation to complete the cycle may result in display of nonfunctioning behaviors indicative of frustration (Dawkins, 1988; Zobel et al., 2015). Work on human subjects found that an absence in the ability to manage or control one's environment is associated with mental health problems such as depression (Franks et al., 2016).

The provision of shade to cows under heat stress conditions is an essential component of heat management and results in an increased proportion (from 19 to 24\%) of animals ruminating (Blackshaw and Blackshaw,
1994), higher milk yield (West, 2003), and decreased body temperatures compared with unshaded animals (Kendall et al., 2006). Dairy cattle demonstrate a strong need to control their thermoregulation by seeking and spending the majority of their time standing in shaded pasture or a comparable housing system (Schütz et al., 2008; Vizzotto et al., 2015), even when deprived of lying for $12 \mathrm{~h}$ (Schütz et al., 2008).

We speculate that heat stress episodes may initially cause cows to experience frustration as they experience conflict as to whether they should lie down to rest or remain standing to thermoregulate. These feelings of frustration may be further exacerbated as the cow has been instinctively conditioned to use thermoregulatory behavior to alleviate heat stress, but the conflicting motivations break the reward cycle and the animal cannot attain the comfort of thermal alleviation. Despite the lack of evidence, we speculate that the malaise initially experienced by dairy cows during heat stress may have profound effects on thermoregulation, because the experienced mental and physical discomfort will supersede any other affective state, even the strong motivation to rest. Moreover, a reduction in the ability to lie down has been shown to increase behaviors indicative of frustration in thermo-neutral cows (Munksgaard and Simonsen, 1996), such as leg stomping, weight repositioning, and butting (Cooper et al., 2007). Future research should examine possible frustration behaviors unique to heat-stressed cows in an effort to more accurately determine the cow's mental state during the progressing stages of thermal illness. Improved understanding of these behaviors can help in the early identification of cows at risk for heat stress.

The frustration-aggression hypothesis states that feelings of frustration can manifest into aggressive behavior (Berkowitz, 1989). Research on human subjects indicates that high temperatures increase aggression by directly increasing hostile, aggressive, and violent thoughts (Anderson, 2001). Aggression has been reported in other livestock such as donkeys working in hot environments (Pritchard et al., 2005), and pigs housed in high temperature barns (Schrøder-Petersen and Simonsen, 2001). A few reports have cited increased aggressive behavior in dairy cattle when animals directly exposed to the sun competed for the opportunity for shade access (Vizzotto et al., 2015). Schütz et al. (2010) reported that the amount of space provided to the animals experiencing heat stress affects aggression, because increases in shade availability per cow result in reduced aggressive interactions. Given that shade appears to be highly valued by cattle in heat stress, efforts should continue to determine how much shade space cattle require to enable cooling without the negative effects of aggression. Social hierarchy also plays a role in the 
harmful effects of heat stress, particularly when access to the resources that enable cooling is restricted. For instance, subordinate cows already have elevated hypothalamic-pituitary-adrenal (HPA) axis activity (Solano et al., 2004), which may be further exacerbated by the increase in aggressive behaviors expressed by dominant cows competing for access to shade. Moreover, on hot days, depending on the location of the water trough, dominant cows have more drinking events and time spent drinking than subordinate cows (Coimbra et al., 2012). Future research should continue to investigate how the social structure of dairy cows influences heat stress coping strategies and competition for resources.

\section{NATURAL LIVING}

The ability to thermoregulate is an evolutionary adaptation that allows mammals to maintain biological functioning (at least to some extent) in spite of environmental temperature fluctuations (Silanikove, 2000). Environmental temperatures have increased by 0.2 to $0.6^{\circ} \mathrm{C}$ since 2000 and are projected to continue to increase a further $5.8^{\circ} \mathrm{C}$ by the end of the century (IPCC, 2007); therefore, we predict that an ever-increasing number of cows will be subjected to heat stress and that taking advantage of the animal's natural ability and morphological differences to thermoregulate will become increasingly important.

\section{Evolutionary Adaptation to Heat Stress}

The modern B. taurus dairy cow differs greatly in her adaptations and ability to cope under heat stress conditions compared with her predecessors. Mitochondrial DNA analysis indicates that $B$. indicus diverged from $B$. taurus between 110,000 and 850,000 years ago, subsequently evolving in tropical Asian regions (Hansen, 2004). In hot, arid climates, the scarcity of rainfall often prevents the continuous growth of plants to be used as feed or solar protection. These environmental features may have contributed to the evolutionary progression of $B$. indicus breeds, leading to the development of morphological, physiological, and cellular traits allowing for improved fitness (Finch, 1986; Hansen, 2004) that facilitate coping under heat stress conditions and promote natural living. Conversely, B. taurus evolved in a more temperate environment and thus, when subjected to high environmental temperatures, may lack adequate heat coping mechanisms (LandaetaHernández et al., 2011).

Evolutionary coping mechanisms in $B$. indicus breeds that improve thermoregulatory efficiency include a greater skin surface to mass ratio, greater skin pigmentation, shorter hair, lighter-colored coats, larger and more numerous sweat glands, and increased skin vascularity (Landaeta-Hernández et al., 2011; Riley et al., 2012). Additionally, hair coat thickness and hair weight per unit surface area are important factors for nonevaporative heat loss. Hair coat is affected by photoperiod, which can regulate seasonal changes in shedding (e.g., thick winter coat for a lighter, thinner summer coat). Bos indicus have shorter and lighter hair compared with $B$. taurus during all seasons of the year (Berman, 2011). However, it is important to note that despite superior thermoregulatory adaptabilities, $B$. indicus breeds are not exempt from the negative effects of heat stress, and can experience compromised welfare at elevated temperatures stemming from increased rectal temperatures and respiratory rates (Srikandakumar and Johnson, 2004).

Bos taurus breeds, such as the Holstein (or its close counterpart, the Holstein Friesian), are at increased risk for heat stress compared with their B. indicus counterparts and, given their lack of functional evolutionary adaptations to maintain normal body temperatures, are at high risk for compromised welfare due to the decline in their ability to live a natural life reflective of their evolutionary environment. Ethical concerns also arise when animals that are not biologically suited to a specific environment are introduced and reared, frequently resulting in suboptimal performance and illness caused by the environment and production pressures.

Numerous anecdotal reports of cows bunching in tight groups in response to elevated heat load may be an adaptive response to an external threat; that is, increased environmental temperature initiates a distress response such as the classic prey response of sequestering the herd (Mooring and Hart, 1992). Using dairy breeds that are better adapted to elevated temperatures, especially in regions where high temperatures are constant, may help to reduce the harmful effects of heat stress (von Keyserlingk et al., 2013).

\section{GENERAL DISCUSSION}

\section{Housing and Thermal Management of Dairy Cows}

Clearly, numerous challenges face dairy cattle, particularly B. taurus breeds, housed in hot environments that are exposed to increasing heat loads. Alterations in housing and management strategies have attempted to mitigate these negative states. Here, we discuss the use of technologies such as fans, misters, and showers but do not address other thermal management strategies (e.g., barn construction materials, bedding, feeding and reproductive management) as these approaches cannot provide immediate thermal relief for dairy cows when challenged by an abrupt environmental heat load. 
Various cooling options for dairy cows exist based on the principles of convection, conduction, radiation, and evaporation. Fan installations, which facilitate air movement and increase convection, have been used to reduce environmental temperatures and mitigate heat stress by decreasing respiratory rate and rectal temperature and increasing DMI (Armstrong, 1994). Other forms of evaporative cooling make use of high-pressure mist injected into fans (which function to cool the microclimate air that the cows inspire) or large water droplets from low-pressure sprinkler systems that completely wet the cow by soaking the hair coat. Both of these systems have been shown to reduce rectal body temperatures and improve DMI, conception rates, and live calf birth rate (West, 2003). Some recent work has looked at providing cows with self-controlled showers (which animals can operate using a pressure-sensitive floor), which provide cooling on an individual animal basis but have the added benefit of reducing overall water usage by the group (Legrand et al., 2011). However, the authors also noted considerable individual variation in the time that cows use this resource. Future research should continue to investigate behavioral responses to water treatments that provide heat abatement but also minimize water usage (Legrand et al., 2011). Physical structures that provide shade such as trees, roofs, or cloth can create more hospitable microclimates for cows because of the reduction in solar radiation exposure and decline in ambient temperature. However, dairy cows show distinct preferences for the type of shade structure depending on the environmental conditions (Schütz et al., 2009), which should be considered when designing farm heat abatement decisions. Barn orientation (depending on geographic location) can also help mitigate heat stress by reducing the insolation and stall surface temperature, which in turn increase the heat transfer from the cow's body back to the environment (Angrecka and Herbut, 2016).

Various intervention techniques have been pursued to improve the coping abilities of heat-stressed cows. In attempts to enhance Holstein genetics with improved thermoregulatory ability, the slick hair gene (SLICK) has been introduced through selective breeding. This gene controls hair length, an important component for evaporative heat loss and efficient transfer of heat to the environment (Dikmen et al., 2008). Although current research has shown promise for this gene, it is unlikely that the rapid introduction of a single gene into the Holstein genome will be able to combat heat stress and confer the myriad of adaptations that $B$. indicus have after 110,000 years of evolution. Moreover, some regions that experience high ambient temperatures in the summer are also prone to very cold temperatures in the winter. In such situations, producers should be cautious when incorporating the slick hair gene into their herd, as short-haired animals will be at a higher risk for cold stress in the winter season, subsequently compromising their welfare.

The alternative management avenues available through gene editing that could result in a cow better able to cope with the challenges associated with heat stress will no doubt increase in number over the next decade. However, despite the advances predicted with these types of technologies, it remains to be seen whether society will accept them in the long run, given the current criticisms regarding the perceived unnaturalness of these types of technologies (see von Keyserlingk et al., 2013 for further discussion on this topic).

\section{Sustainability of Heat Stress Management}

Despite advances in evaporative cooling technology, 2 primary concerns arise with the use of sprinkler systems. First, depending on herd size, large volumes of water are needed for cooling, plus such systems generate equally large amounts of wastewater that must be managed. Sprinkler-system water use can range from $215 \mathrm{~L} / \mathrm{cow}$ per day (Means et al., 1992) to $454.2 \mathrm{~L} / \mathrm{cow}$ per day (Strickland et al., 1989), quantities that may become economically and environmentally unsustainable in the near future. Special attention should also be paid to the locations of dairy farms, as much of the dairy production in the United States has moved to California and the Southwest, where environmental temperatures continue to rise and fresh water supplies are limited (von Keyserlingk et al., 2013). Water for evaporative cooling, drinking water, and water needed during the milking routine are the 3 main uses of potable water on commercial dairies, and decreasing water usage and contamination is critical to the sustainability of the industry (Chen et al., 2015). Second, despite sprinklers greatly reducing respiratory rate and insect avoidance behaviors (tail flicks, hoof stamps, skin twitches, and head throws), their use also results in increased cow avoidance behaviors such as changing head position, lowering of the head, and placing the head outside the wooden structure away from the sprinklers (Schütz et al., 2011; Chen et al., 2016). We speculate that cattle likely never evolved to seek out rain as a means to cool; thus, exposing animals to water goes against the natural living of dairy cows. In contrast, cattle appear to prefer to seek out shelter in efforts to avoid adverse weather conditions (Vandenheede et al., 1995). However, optimal cooling strategy designs that take into consideration the cow's perspective have only recently begun to be explored and such approaches should be strongly encouraged. The dairy industry would benefit from additional research that examines the economic 
benefit of "cow-focused" heat abatement strategies to determine which method is most economical in terms of increased production metrics (i.e., minimize milk production loss and sustain conception rates) but also ensures a reasonable quality of life for the cow and minimizes the environmental impact.

Ideally, for solutions derived from animal welfare science to be sustainable, they must satisfy all 3 constructs of welfare (Figure 1), and we challenge those working to improve heat management practices for production animals, including confinement-housed dairy cattle, to incorporate all components of animal welfare, not just individual elements, into management solutions. Moreover, adoption of these practices will be much quicker if those working closest to animals perceive these solutions to be practical.

\section{CONCLUSIONS}

Heat stress has become a major concern for dairy producers because of the associated decreases in milk production and large economic losses. Classically, research on this important topic has focused on tracking changes in biological functioning and health as the cow copes in the hot environment. However, to ensure high standards of welfare for dairy cattle, a broader approach is needed that includes the importance of considering how heat stress may also cause negative affective states and that heat mitigation strategies should, where possible, consider the natural adaptions of cows to aversive conditions. Gaps in the literature highlight the need for research into the pain, frustration, aggression, and malaise associated with heat stress, specifically increased hunger and thirst in the short term and foot lesions and lameness in the long term. Additionally, we have highlighted the drastic deviation of the modern dairy cow, particularly the $B$. taurus animal, from their evolutionary ancestors and the resulting challenges faced by the modern animal when subjected to heat stress. Future research must examine the possibility of adopting cattle breeds that are better equipped for hot environments, thus minimizing the duration of compromised welfare. This literature review was written to provide readers with a clear sense of contemporary heat stress issues from the perspective of animal welfare and the need for clear scientific assessment and intervention.

\section{ACKNOWLEDGMENTS}

The authors thank Arielle J. Martin, who assisted with the design and conception of Figure 1. We thank Daniel M. Weary [Animal Welfare Program, University of British Columbia (UBC), Vancouver, BC, Canada] for his helpful suggestions on an earlier draft of this paper. General funding for UBC's Animal Welfare Program comes from an NSERC Industrial Research Chair with industry contributions from the Dairy Farmers of Canada (Ottawa, ON, Canada), British Columbia Dairy Association (Burnaby, BC Canada), Westgen Endowment Fund (Milner, BC, Canada), Intervet Canada Corporation (Kirkland, QC, Canada), Novus International Inc. (Oakville, ON, Canada), Zoetis (Kirkland, QC, Canada), BC Cattle Industry Development Fund (Kamloops, BC, Canada), Alberta Milk (Edmonton, AB, Canada), Valacta (St. Anne-de-Bellevue, QC, Canada), and CanWest DHI (Guelph, ON, Canada).

\section{REFERENCES}

Allen, J. D., L. W. Hall, R. J. Collier, and J. F. Smith. 2015. Effect of core body temperature, time of day, and climate conditions on behavioral patterns of lactating dairy cows experiencing mild to moderate heat stress. J. Dairy Sci. 98:118-127. https://doi.org/10 $.3168 /$ jds.2013-7704.

Anderson, C. A. 2001. Heat and violence. Curr. Dir. Psychol. Sci. 10:33-38. https://doi.org/10.1111/1467-8721.00109.

Angrecka, S., and P. Herbut. 2016. Impact of barn orientation on insolation and temperature of stalls surface. Ann. Anim. Sci. $16: 887-896$.

Armstrong, D. V. 1994. Heat stress interaction with shade and cooling. J. Dairy Sci. 77:2044-2050. https://doi.org/10.3168/jds.s0022 -0302(94)77149-6.

Berkowitz, L. 1989. Frustration-aggression hypothesis: Examination and reformulation. Psychol. Bull. 106:59 https://doi.org/10.1037/ 0033-2909.106.1.59.

Berman, A. 2011. Invited review: Are adaptations present to support dairy cattle productivity in warm climates? J. Dairy Sci. 94:21472158. https://doi.org/10.3168/jds.2010-3962.

Bertenshaw, C., P. Rowlinson, H. Edge, S. Douglas, and R. Shiel. 2008. The effect of different degrees of 'positive' human-animal interaction during rearing on the welfare and subsequent production of commercial dairy heifers. Appl. Anim. Behav. Sci. 114:65-75. https://doi.org/10.1016/j.applanim.2007.12.002.

Bewley, J. M., M. E. Einstein, M. W. Grott, and M. M. Schutz. 2008. Comparison of reticular and rectal core body temperatures in lactating dairy cows. J. Dairy Sci. 91:4661-4672.

Blackshaw, J. K., and A. W. Blackshaw. 1994. Heat stress in cattle and the effect of shade on production and behavior: A review. Anim. Prod. Sci. 34:285-295. https://doi.org/10.1071/ea9940285.

Bohmanova, J., I. Misztal, and J. B. Cole. 2007. Temperature-humidity indices as indicators of milk production losses due to heat stress. J. Dairy Sci. 90:1947-1956.

Boissy, A., C. Arnould, E. Chaillou, L. Désiré, C. Duvaux-Ponter, L. Greiveldinger, C. Leterrier, S. Richard, S. Roussel, H. Saint-Dizier, and M. C. Meunier-Salaün. 2007. Emotions and cognition: A new approach to animal welfare. Anim. Welf. 16:37-43.

Cain, J. W. III, P. R. Krausman, S. S. Rosenstock, and J. C. Turner. 2006. Mechanisms of thermoregulation and water balance in desert ungulates. Wildl. Soc. Bull. 34:570-581. https://doi.org/10.2193/ 0091-7648(2006)34[570:motawb]2.0.co;2.

Charlton, G. L., S. M. Rutter, M. East, and L. A. Sinclair. 2013. The motivation of dairy cows for access to pasture. J. Dairy Sci. 96:4387-4396. https://doi.org/10.3168/jds.2012-6421. PubMed

Chebel, R. C., J. E. P. Santos, J. P. Reynolds, R. L. A. Cerri, S. O. Juchem, and M. Overton. 2004. Factors affecting conception rate after artificial insemination and pregnancy loss in lactating dairy cows. Anim. Reprod. Sci. 84:239-255. https://doi.org/10.1016/j .anireprosci.2003.12.012.

Chen, J. M., K. E. Schütz, and C. B. Tucker. 2015. Cooling cows efficiently with sprinklers: Physiological responses to water spray. J. Dairy Sci. 98:6925-6938. https://doi.org/10.3168/jds.2015-9434. 
Chen, J. M., K. E. Schütz, and C. B. Tucker. 2016. Sprinkler flow rate affects dairy cattle preferences, heat load, and insect deterrence behavior. Appl. Anim. Behav. Sci. 182:1-8.

Coimbra, P. A. D., L. C. P. Machado Filho, and M. J. Hötzel. 2012. Effects of social dominance, water trough location and shade availability on drinking behavior of cows on pasture. Appl. Anim. Behav. Sci. 139:175-182. https://doi.org/10.1016/j.applanim.2012.04 009 .

Collard, B. L., P. J. Boettcher, J. C. M. Dekkers, D. Petitclerc, and L. R. Schaeffer. 2000. Relationships between energy balance and health traits of dairy cattle in early lactation. J. Dairy Sci. 83:2683-2690.

Collier, R. J., R. M. Eley, A. K. Sharma, R. M. Pereira, and D. E. Buffington. 1981. Shade management in subtropical environment for milk yield and composition in Holstein and Jersey cows. J. Dairy Sci. 64:844-849. https://doi.org/10.3168/jds.s0022-0302(81)82656 -2 .

Collins, K. J., and J. S. Weiner. 1968. Endocrinological aspects of exposure to high environmental temperatures. Physiol. Rev. 48:785839.

Cook, N. B., T. B. Bennett, and K. V. Nordlund. 2004a. Effect of free stall surface on daily activity patterns in dairy cows with relevance to lameness prevalence. J. Dairy Sci. 87:2912-2922. https://doi .org/10.3168/jds.s0022-0302(04)73422-0.

Cook, N. B., R. L. Mentink, T. B. Bennett, and K. Burgi. 2007. The effect of heat stress and lameness on time budgets of lactating dairy cows. J. Dairy Sci. 90:1674-1682. https://doi.org/10.3168/ jds.2006-634.

Cook, N. B., and K. V. Nordlund. 2009. The influence of the environment on dairy cow behavior, claw health and herd lameness dynamics. Vet. J. 179:360-369. https://doi.org/10.1016/j.tvjl.2007 .09 .016 .

Cook, N. B., K. V. Nordlund, and G. R. Oetzel. 2004b. Environmental influences on claw horn lesions associated with laminitis and subacute ruminal acidosis in dairy cows. J. Dairy Sci. 87(E. Suppl.):E36-E46. https://doi.org/10.3168/jds.s0022 -0302(04)70059-4.

Cooper, M. D., D. R. Arney, and C. J. C. Phillips. 2007. Two- or fourhour lying deprivation on the behavior of lactating dairy cows. J. Dairy Sci. 90:1149-1158. https://doi.org/10.3168/jds.s0022 -0302(07)71601-6.

Cray, C., J. Zaias, and N. H. Altman. 2009. Acute phase response in animals: A review. Comp. Med. 59:517-526.

D'Eath, R. B., B. J. Tolkamp, I. Kyriazakis, and A. B. Lawrence. 2009. Freedom from hunger' and preventing obesity: The animal welfare implications of reducing food quantity or quality. Anim. Behav. 77:275-288. https://doi.org/10.1016/j.anbehav.2008.10.028.

Daros, R. R., J. H. C. Costa, M. A. G. von Keyserlingk, M. J. Hötzel, and D. M. Weary. 2014. Separation from the dam causes negative judgement bias in dairy calves. PLoS One 9:e98429. https://doi .org/10.1371/journal.pone.0098429.

Dawkins, M. S. 1988. Behavioral deprivation: A central problem in animal welfare. Appl. Anim. Behav. Sci. 20:209-225. https://doi .org/10.1016/0168-1591(88)90047-0.

de Jonge, F. H., S.-L. Tilly, A. M. Baars, and B. M. Spruijt. 2008. On the rewarding nature of appetitive feeding behavior in pigs (Sus scrofa): Do domesticated pigs contrafreeload? Appl. Anim. Behav. Sci. 114:359-372. https://doi.org/10.1016/j.applanim.2008.03.006.

De Rensis, F., I. Garcia-Ispierto, and F. López-Gatius. 2015. Seasonal heat stress: Clinical implications and hormone treatments for the fertility of dairy cows. Theriogenology 84:659-666.

De Rensis, F., and R. J. Scaramuzzi. 2003. Heat stress and seasonal effects on reproduction in the dairy cow-A review. Theriogenology 60:1139-1151. https://doi.org/10.1016/s0093-691x(03)00126-2.

Dikmen, S., E. Alava, E. Pontes, J. M. Fear, B. Y. Dikmen, T. A. Olson, and P. J. Hansen. 2008. Differences in thermoregulatory ability between slick-haired and wild-type lactating Holstein cows in response to acute heat stress. J. Dairy Sci. 91:3395-3402. https:// doi.org/10.3168/jds.2008-1072.

Dikmen, S., and P. J. Hansen. 2009. Is the temperature-humidity index the best indicator of heat stress in lactating dairy cows in a subtropical environment? J. Dairy Sci. 92:109-116. https://doi .org $/ 10.3168 /$ jds.2008-1370

Duncan, I. J. H. 2004. Concept of welfare based on feelings. Pages 85-100 in The Well-Being of Farm Animals. G. J. Benson and B. E. Rollin, ed. Blackwell, Oxford, UK. https://doi.org/10.1002/ 9780470344859.ch5.

Ettinger, S. J., and E. C. Feldman. 2009. Textbook of Veterinary Internal Medicine. Elsevier Health Sciences, Philadelphia, PA.

Ferrell, C. L., and T. G. Jenkins. 1985. Cow type and the nutritional environment: Nutritional aspects. J. Anim. Sci. 61:725-741. https://doi.org/10.2527/jas1985.613725x.

Finch, V. A. 1986. Body temperature in beef cattle: Its control and relevance to production in the tropics. J. Anim. Sci. 62:531-542. https://doi.org/10.2527/jas1986.622531x.

Flower, F. C., M. Sedlbauer, E. Carter, M. A. G. von Keyserlingk, D. J. Sanderson, and D. M. Weary. 2008. Analgesics improve the gait of lame dairy cattle. J. Dairy Sci. 91:3010-3014. https://doi.org/ 10.3168/jds.2007-0968.

Franks, B., F. A. Champagne, and E. T. Higgins. 2013. How enrichment affects exploration trade-offs in rats: Implications for welfare and well-being. PLoS One 8:e83578. https://doi.org/10.1371/ journal.pone.0083578.

Franks, B., C. Chen, K. Manley, and E. T. Higgins. 2016. Effective challenge regulation coincides with promotion focus-related success and emotional well-being. J Happiness Stud. 17:981-994. https://doi.org/10.1007/s10902-015-9627-7.

Franks, B., and E. T. Higgins. 2012. Effectiveness in humans and other animals: A common basis for well-being and welfare. Adv. Exp. Soc. Psychol. 46:285.

Fraser, D., D. M. Weary, E. A. Pajor, and B. N. Milligan. 1997. A scientific conception of animal welfare that reflects ethical concerns. Anim. Welf. 6:187-205.

Ganong, W. F. 2005. Central regulation of visceral function: Thirst. Pages 240-241 in Review of Medical Physiology. 22nd ed. Appleton and Lange, Stamford, CT.

Gröhn, Y. T., D. J. Wilson, R. N. González, J. A. Hertl, H. Schulte, G. Bennett, and Y. H. Schukken. 2004. Effect of pathogen-specific clinical mastitis on milk yield in dairy cows. J. Dairy Sci. 87:3358 3374. https://doi.org/10.3168/jds.s0022-0302(04)73472-4.

Hansen, P. J. 1985. Seasonal modulation of puberty and the postpartum anestrus in cattle: A review. Livest. Prod. Sci. 12:309-327.

Hansen, P. J. 2004. Physiological and cellular adaptations of zebu cattle to thermal stress. Anim. Reprod. Sci. 82-83:349-360. https:// doi.org/10.1016/s0378-4320(04)00066-1.

Hansen, P. J., and C. F. Aréchiga. 1999. Strategies for managing reproduction in the heat-stressed dairy cow. J. Anim. Sci. 77:36. https://doi.org/10.2527/1997.77suppl_236x.

Hassan, A., and J. D. Roussel. 1975. Effect of protein concentration in the diet on blood composition and productivity of lactating Holstein cows under thermal stress. J. Agric. Sci. 85:409-415. https:// doi.org/10.1017/s0021859600062286.

Hessle, A., M. Rutter, and K. Wallin. 2008. Effect of breed, season and pasture moisture gradient on foraging behavior in cattle on seminatural grasslands. Appl. Anim. Behav. Sci. 111:108-119. https:// doi.org/10.1016/j.applanim.2007.05.017.

Hu, H., Y. Zhang, N. Zheng, J. Cheng, and J. Wang. 2016. The effect of heat stress on gene expression and synthesis of heat-shock and milk proteins in bovine mammary epithelial cells. Anim. Sci. J. 87:84-91. https://doi.org/10.1111/asj.12375.

IASP (International Association for the Study of Pain). 1994. Part III: Pain terms, a current list with definitions and notes on usage. Pages 209-214 in Classification of Chronic Pain. H. Merskey and N Bogduk, ed. IASP Press, Seattle WA.

IPCC (Intergovernmental Panel on Climate Change). 2007. Summary for policy makers. Page 23. Cambridge Press, Cambridge, UK.

Ito, K., M. A. G. von Keyserlingk, S. J. LeBlanc, and D. M. Weary. 2010. Lying behavior as an indicator of lameness in dairy cows. J. Dairy Sci. 93:3553-3560. https://doi.org/10.3168/jds.2009-2951.

Jensen, M. B., L. J. Pedersen, and L. Munksgaard. 2005. The effect of reward duration on demand functions for rest in dairy heifers and lying requirements as measured by demand functions. Appl. 
Anim. Behav. Sci. 90:207-217. https://doi.org/10.1016/j.applanim .2004.08.006.

Kadzere, C. T., M. R. Murphy, N. Silanikove, and E. Maltz. 2002. Heat stress in lactating dairy cows: A review. Livest. Prod. Sci. 77:59-91. https://doi.org/10.1016/s0301-6226(01)00330-x.

Keeling, L., B. Algers, H. Blokhuis, A. Boissy, L. Lidfors, M. Mendl, R. Opperman Moe, E. Paul, K. Uvnäs-Moberg, and A. Zanella. 2008. Looking on the bright side of life: Reward, positive emotions and animal welfare. Page 3 in 2008 Proc. 42nd Congr. Int. Soc. Appl. Ethol., Dublin, Ireland. Wageningen Academic Publishers, Wageningen, the Netherlands.

Kendall, P. E., P. P. Nielsen, J. R. Webster, G. A. Verkerk, R. P. Littlejohn, and L. R. Matthews. 2006. The effects of providing shade to lactating dairy cows in a temperate climate. Livest. Sci. 103:148-157. https://doi.org/10.1016/j.livsci.2006.02.004.

Landaeta-Hernández, A., S. Zambrano-Nava, J. P. Hernández-Fonseca, R. Godoy, M. Calles, J. L. Iragorri, L. Añez, M. Polanco, M. Montero-Urdaneta, and T. Olson. 2011. Variability of hair coat and skin traits as related to adaptation in Criollo Limonero cattle. Trop. Anim. Health Prod. 43:657-663.

LeDoux, J. E. 1995. Emotion: Clues from the brain. Annu. Rev. Psychol. 46:209-235. https://doi.org/10.1146/annurev.psych.46.1.209.

Legrand, A., K. E. Schütz, and C. B. Tucker. 2011. Using water to cool cattle: Behavioral and physiological changes associated with voluntary use of cow showers. J. Dairy Sci. 94:3376-3386.

Lei, L., L. Hepeng, L. Xianlei, J. Hongchao, L. Hai, A. Sheikhahmadi, W. Yufeng, and S. Zhigang. 2013. Effects of acute heat stress on gene expression of brain-gut neuropeptides in broiler chickens (Gallus gallus domesticus). J. Anim. Sci. 91:5194-5201. https://doi .org/10.2527/jas.2013-653.

Lindqvist, C., and P. Jensen. 2008. Effects of age, sex and social isolation on contrafreeloading in red junglefowl (Gallus gallus) and White Leghorn fowl. Appl. Anim. Behav. Sci. 114:419-428. https://doi.org/10.1016/j.applanim.2008.03.002.

Linvill, D. E., and F. E. Pardue. 1992. Heat stress and milk production in the South Carolina coastal plains. J. Dairy Sci. 75:2598-2604. https://doi.org/10.3168/jds.s0022-0302(92)78022-9.

Mader, T. L., M. S. Davis, and T. Brown-Brandl. 2006. Environmental factors influencing heat stress in feedlot cattle. J. Anim. Sci. 84:712-719. https://doi.org/10.2527/2006.843712x.

Means, S. L., R. A. Bucklin, R. A. Nordstedt, D. K. Beede, D. R. Bray, C. J. Wilcox, and W. K. Sanchez. 1992. Water application rates for a sprinkler and fan dairy cooling system in hot, humid climates. Appl. Eng. Agric. 8:375-379. https://doi.org/10.13031/ 2013.26507.

Mooring, M. S., and B. L. Hart. 1992. Animal grouping for protection from parasites: Selfish herd and encounter-dilution effects. Behaviour 123:173-193. https://doi.org/10.1163/156853992x00011.

Munksgaard, L., and H. B. Simonsen. 1996. Behavioral and pituitary adrenal-axis responses of dairy cows to social isolation and deprivation of lying down. J. Anim. Sci. 74:769-778. https://doi.org/10 $.2527 / 1996.744769 x$.

NRC. 2001. Nutrient Requirements of Dairy Cattle. 7th rev. ed. Natl. Acad. Sci., Washington, DC.

Nybo, L., and B. Nielsen. 2001. Hyperthermia and central fatigue during prolonged exercise in humans. J. Appl. Physiol. 91:1055-1060. https://doi.org/10.1111/j.1469-7793.2001.t01-1-00279.x.

Orihuela, A. 2000. Some factors affecting the behavioral manifestation of oestrus in cattle: A review. Appl. Anim. Behav. Sci. 70:1-16. https://doi.org/10.1016/s0168-1591(00)00139-8.

Pearce, S. C., M. V. Sanz-Fernandez, J. H. Hollis, L. H. Baumgard, and N. K. Gabler. 2014. Short-term exposure to heat stress attenuates appetite and intestinal integrity in growing pigs. J. Anim. Sci. 92:5444-5454. https://doi.org/10.2527/jas.2014-8407.

Pereira, M. H. C., A. D. P. Rodrigues, T. Martins, W. V. C. Oliveira, P. S. A. Silveira, M. C. Wiltbank, and J. L. M. Vasconcelos. 2013. Timed artificial insemination programs during the summer in lactating dairy cows: Comparison of the 5 -d Cosynch protocol with an estrogen/progesterone-based protocol. J. Dairy Sci. 96:69046914. https://doi.org/10.3168/jds.2012-6260.
Pritchard, J. C., A. R. Barr, and H. R. Whay. 2006. Validity of a behavioral measure of heat stress and a skin tent test for dehydration in working horses and donkeys. Equine Vet. J. 38:433-438. https://doi.org/10.2746/042516406778400646.

Pritchard, J. C., A. C. Lindberg, D. C. J. Main, and H. R. Whay. 2005. Assessment of the welfare of working horses, mules and donkeys, using health and behavior parameters. Prev. Vet. Med. 69:265283. https://doi.org/10.1016/j.prevetmed.2005.02.002.

Purwanto, B. P., Y. Abo, R. Sakamoto, F. Furumoto, and S. Yamamoto. 1990. Diurnal patterns of heat production and heart rate under thermoneutral conditions in Holstein Friesian cows differing in milk production. J. Agric. Sci. 114:139 https://doi.org/10.1017/ s0021859600072117.

Renaudeau, D., A. Collin, S. Yahav, V. De Basilio, J. L. Gourdine, and R. J. Collier. 2012. Adaptation to hot climate and strategies to alleviate heat stress in livestock production. Animal 6:707-728. https://doi.org/10.1017/s1751731111002448.

Rhoads, M. L., R. P. Rhoads, M. J. VanBaale, R. J. Collier, S. R. Sanders, W. J. Weber, B. A. Crooker, and L. H. Baumgard. 2009. Effects of heat stress and plane of nutrition on lactating Holstein cows: I. Production, metabolism, and aspects of circulating somatotropin. J. Dairy Sci. 92:1986-1997. https://doi.org/10.3168/ jds.2008-1641.

Rhoads, R. P., A. J. La Noce, J. B. Wheelock, and L. H. Baumgard. 2011. Short communication: Alterations in expression of gluconeogenic genes during heat stress and exogenous bovine somatotropin administration. J. Dairy Sci. 94:1917-1921. https://doi.org/10 .3168/jds.2010-3722.

Riley, D. G., C. C. Chase, S. W. Coleman, and T. A. Olson. 2012. Genetic assessment of rectal temperature and coat score in Brahman, Angus, and Romosinuano crossbred and straightbred cows and calves under subtropical summer conditions. Livest. Sci. 148:109118. https://doi.org/10.1016/j.livsci.2012.05.017.

Roche, J. R., N. C. Friggens, J. K. Kay, M. W. Fisher, K. J. Stafford, and D. P. Berry. 2009. Invited review: Body condition score and its association with dairy cow productivity, health, and welfare. J. Dairy Sci. 92:5769-5801. https://doi.org/10.3168/jds.2009-2431.

Roth, Z., A. Arav, A. Bor, Y. Zeron, R. Braw-Tal, and D. Wolfenson. 2001. Improvement of quality of oocytes collected in the autumn by enhanced removal of impaired follicles from previously heat-stressed cows. Reproduction 122:737-744. https://doi.org/10 $.1530 /$ rep.0.1220737.

Roussel, A. J. 1999. Fluid therapy in mature cattle. Vet. Clin. North Am. Food Anim. Pract. 15:545-557. https://doi.org/10.1016/ s0749-0720(15)30163-8.

Rushen, J., L. Munksgaard, P. G. Marnet, and A. M. De Passillé. 2001. Human contact and the effects of acute stress on cows at milking. Appl. Anim. Behav. Sci. 73:1-14. https://doi.org/10.1016/s0168 -1591(01)00105-8.

Schär, C., P. L. Vidale, D. Lüthi, C. Frei, C. Häberli, M. A. Liniger, and C. Appenzeller. 2004. The role of increasing temperature variability in European summer heatwaves. Nature 427:332-336. https://doi.org/10.1038/nature02300.

Schrøder-Petersen, D. L., and H. B. Simonsen. 2001. Tail biting in pigs. Vet. J. 162:196-210.

Schüller, L. K., O. Burfeind, and W. Heuwieser. 2014. Impact of heat stress on conception rate of dairy cows in the moderate climate considering different temperature-humidity index thresholds, periods relative to breeding, and heat load indices. Theriogenology 81:1050-1057. https://doi.org/10.1016/j.theriogenology.2014.01 .029 .

Schütz, K. E., N. R. Cox, and L. R. Matthews. 2008. How important is shade to dairy cattle? Choice between shade or lying following different levels of lying deprivation. Appl. Anim. Behav. Sci. 114:307-318. https://doi.org/10.1016/j.applanim.2008.04.001.

Schütz, K. E., A. R. Rogers, N. R. Cox, and C. B. Tucker. 2009. Dairy cows prefer shade that offers greater protection against solar radiation in summer: Shade use, behavior, and body temperature. Appl. Anim. Behav. Sci. 116:28-34.

Schütz, K. E., A. R. Rogers, N. R. Cox, J. R. Webster, and C. B Tucker. 2011. Dairy cattle prefer shade over sprinklers: Effects 
on behavior and physiology. J. Dairy Sci. 94:273-283. https://doi .org/10.3168/jds.2010-3608.

Schütz, K. E., A. R. Rogers, Y. A. Poulouin, N. R. Cox, and C. B. Tucker. 2010. The amount of shade influences the behavior and physiology of dairy cattle. J. Dairy Sci. 93:125-133. https://doi .org/10.1016/s0031-9384(98)00059-6.

Silanikove, N. 2000. Effects of heat stress on the welfare of extensively managed domestic ruminants. Livest. Prod. Sci. 67:1-18. https:// doi.org/10.1016/s0301-6226(00)00162-7.

Solano, J., F. Galindo, A. Orihuela, and C. S. Galina. 2004. The effect of social rank on the physiological response during repeated stressful handling in Zebu cattle (Bos indicus). Physiol. Behav. 82:679-683. https://doi.org/10.1016/j.physbeh.2004.06.005.

Song, Z., L. Liu, A. Sheikhahmadi, H. Jiao, and H. Lin. 2012. Effect of heat exposure on gene expression of feed intake regulatory peptides in laying hens. J. Biomed. Biotechnol. 2012:484869. https:// doi.org/10.1155/2012/484869.

Spiers, D. E., J. N. Spain, J. D. Sampson, and R. P. Rhoads. 2004. Use of physiological parameters to predict milk yield and feed intake in heat-stressed dairy cows. J. Therm. Biol. 29:759-764. https://doi .org/10.1016/j.jtherbio.2004.08.051

Špinka, M. 2006. How important is natural behavior in animal farming systems? Appl. Anim. Behav. Sci. 100:117-128. https://doi.org/10 .1016/j.applanim.2006.04.006

Špinka, M., and F. Wemelsfelder. 2011. Environmental challenge and animal agency. Anim. Welf. 2:27-44.

Spooner, J. M., C. A. Schuppli, and D. Fraser. 2012. Attitudes of Canadian beef producers toward animal welfare. Anim. Welf. 21:273283. https://doi.org/10.7120/09627286.21.2.273.

Srikandakumar, A., and E. H. Johnson. 2004. Effect of heat stress on milk production, rectal temperature, respiratory rate and blood chemistry in Holstein, Jersey and Australian Milking Zebu cows. Trop. Anim. Health Prod. 36:685-692. https://doi.org/10.1023/b: trop.0000042868.76914.a9.

St-Pierre, N. R., B. Cobanov, and G. Schnitkey. 2003. Economic losses from heat stress by US livestock industries. J. Dairy Sci. 86(E. Suppl.):E52-E77. https://doi.org/10.3168/jds.s0022 -0302(03)74040-5.

Strickland, J. T., R. A. Bucklin, R. A. Nordstedt, D. K. Beede, and D. R. Bray. 1989. Sprinkler and fan cooling system for dairy cows in hot, humid climates. Appl. Eng. Agric. 5:231-236. https://doi .org $/ 10.13031 / 2013.26507$.

Te Velde, H., N. Aarts, and C. van Workum. 2002. Dealing with ambivalence: farmers' and consumers' perceptions of animal welfare in livestock breeding. J. Agric. Environ. Ethics 15:203-219.

Thom, E. C. 1959. The discomfort index. Weatherwise 12:57-69.

Thomas, T. J., D. M. Weary, and M. C. Appleby. 2001. Newborn and 5-week-old calves vocalize in response to milk deprivation. Appl. Anim. Behav. Sci. 74:165-173. https://doi.org/10.1016/s0168 -1591(01)00164-2.

Vandenheede, M., B. Nicks, R. Shehi, B. Canart, I. Dufrasne, R. Biston, and P. Lecomte. 1995. Use of a shelter by grazing fattening bulls: Effect of climatic factors. Anim. Sci. 60:81-85. https://doi org/10.1017/s135772980000816x.

Ventura, B. A., M. A. G. von Keyserlingk, and D. M. Weary. 2015. Animal welfare concerns and values of stakeholders within the dairy industry. J. Agric. Environ. Ethics 28:109-126. https://doi.org/10 $.1007 / \mathrm{s} 10806-014-9523-\mathrm{x}$

Verbeek, E., J. R. Waas, M. H. Oliver, L. M. McLeay, D. M. Ferguson, and L. R. Matthews. 2012. Motivation to obtain a food reward of pregnant ewes in negative energy balance: Behavioral, metabolic and endocrine considerations. Horm. Behav. 62:162-172.

Vizzotto, E. F., V. Fischer, A. Thaler Neto, A. S. Abreu, M. T. Stumpf, D. Werncke, F. A. Schmidt, and C. M. McManus. 2015. Access to shade changes behavioral and physiological attributes of dairy cows during the hot season in the subtropics. Animal 9:1559-1566.

von Keyserlingk, M. A. G., A. A. Cestari, B. Franks, J. A. Fregonesi, and D. M. Weary. 2017. Dairy cows value access to pasture as highly as fresh feed. Sci. Rep. 7:44953 https://doi.org/10.1038/ srep44953.

von Keyserlingk, M. A. G., and M. J. Hötzel. 2015. The ticking clock: Addressing farm animal welfare in emerging countries. J. Agric. Environ. Ethics 28:179-195.

von Keyserlingk, M. A. G., N. P. Martin, E. Kebreab, K. F. Knowlton, R. J. Grant, M. Stephenson, C. J. Sniffen, J. P. Harner, A. D. Wright, and S. I. Smith. 2013. Invited review: Sustainability of the US dairy industry. J. Dairy Sci. 96:5405-5425.

von Keyserlingk, M. A. G., J. Rushen, A. M. de Passillé, and D. M. Weary. 2009. Invited review: The welfare of dairy cattle-Key concepts and the role of science. J. Dairy Sci. 92:4101-4111. https:// doi.org/10.3168/jds.2012-6354.

Watts, J. M., and J. M. Stookey. 2000. Vocal behavior in cattle: The animal's commentary on its biological processes and welfare. Appl. Anim. Behav. Sci. 67:15-33. https://doi.org/10.1016/s0168 -1591(99)00108-2.

Weary, D. M., P. Droege, and V. A. Braithwaite. 2017. Chapter 2: Behavioural evidence of felt emotions: Approaches, inferences and refinements. Adv. Stud. Behav. 49:27-48. https://doi.org/10.1016/ bs.asb.2017.02.002.

Weary, D. M., and D. Fraser. 1995. Calling by domestic piglets: Reliable signals of need? Anim. Behav. 50:1047-1055.

Weary, D. M., L. Niel, F. C. Flower, and D. Fraser. 2006. Identifying and preventing pain in animals. Appl. Anim. Behav. Sci. 100:6476. https://doi.org/10.1016/j.applanim.2006.04.013.

West, J. W. 2003. Effects of heat-stress on production in dairy cattle. J. Dairy Sci. 86:2131-2144. https://doi.org/10.3168/jds.s0022 $-0302(03) 73803-\mathrm{x}$

Westwood, C. T., I. J. Lean, and J. K. Garvin. 2002. Factors influencing fertility of Holstein dairy cows: a multivariate description. J. Dairy Sci. 85:3225-3237. https://doi.org/10.3168/jds.s0022 -0302(02)74411-1.

Whay, H. R., A. E. Waterman, A. J. F. Webster, and J. K. O'Brien. 1998. The influence of lesion type on the duration of hyperalgesia associated with hind limb lameness in dairy cattle. Vet. J. 156:2329. https://doi.org/10.1016/s1090-0233(98)80058-0.

White, F. J., R. P. Wettemann, M. L. Looper, T. M. Prado, and G. L. Morgan. 2002. Seasonal effects on estrous behavior and time of ovulation in nonlactating beef cows. J. Anim. Sci. 80:3053-3059. https://doi.org/10.2527/2002.80123053x.

Wilks, D. L., C. E. Coppock, J. K. Lanham, K. N. Brooks, C. C. Baker, W. L. Bryson, R. G. Elmore, and R. A. Stermer. 1990 Responses of lactating Holstein cows to chilled drinking water in high ambient temperatures. J. Dairy Sci. 73:1091-1099. https:// doi.org/10.3168/jds.s0022-0302(90)78768-1.

Zobel, G., D. M. Weary, K. E. Leslie, and M. A. G. von Keyserlingk. 2015. Invited review: Cessation of lactation: Effects on animal welfare. J. Dairy Sci. 98:8263-8277. https://doi.org/10.3168/jds.2015 -9617 . 